\title{
Anterolateral Thigh Thickness Measurement in Positron Emission Tomography-Computed Tomography for the Prediction of Free Flap Reconstruction Outcomes in Head and Neck Cancer
}

\author{
Myung Jin Ban ${ }^{1}$, Jae Hong Park ${ }^{1}$, Hyung Kwon Byeon ${ }^{2}$, Jae Won Chang ${ }^{3}$, Jeong Hyun Ahn ${ }^{4}$, \\ Ji-Hoon Kim ${ }^{2}$, Won Shik Kim², Yoon Woo Koh${ }^{2}$, Se-Heon Kim², and Eun Chang Choi ${ }^{2}$ \\ ${ }^{1}$ Department of Otorhinolaryngology-Head and Neck Surgery, Soonchunhyang University College of Medicine, Cheonan; and \\ ${ }^{2}$ Department of Otorhinolaryngology, Yonsei University College of Medicine, Seoul; and \\ ${ }^{3}$ Department of Otorhinolaryngology-Head and Neck Surgery, School of Medicine, Chungnam National University, Daejeon; and \\ ${ }^{4}$ Department of Otorhinolaryngology, College of Medicine, Konyang University, Daejon, Korea
}

두경부 암 수술후 전외측 대퇴 유리피판 재건술의 결과 예상을 위한 Positron Emission

Tomography-Computed Tomography에서 전외측 대퇴의 두께 측정

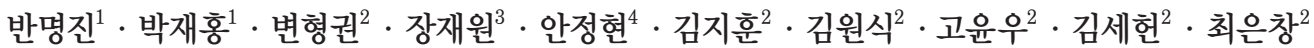

순천향대학교 의과대학 이비인후-두경부외과학교실, ${ }^{1}$ 연세대학교 의과대학 이비인후과학교실,

충남대학교 의과대학 이비인후-두경부외과학교실, ${ }^{3}$ 건양대학교 의과대학 이비인후과학교실 ${ }^{4}$

Received July 18, 2016

Revised September 9, 2016

Accepted September 21, 2016

Address for correspondence

Won Shik Kim, MD

Department of Otorhinolaryngology,

Yonsei University

College of Medicine,

50 Yonsei-ro, Seodaemun-gu,

Seoul 03722, Korea

Tel $+82-2-2228-3627$

Fax $+82-2-393-0580$

E-mail WSKIM78@yuhs.ac
Background and Objectives Anterolateral thigh (ALT) flaps are commonly used for head and neck surgery reconstruction. However, a thick ALT often leads to long operation times. Therefore, ALT thickness on a preoperative non contrast image of positron emission tomography-computed tomography (PET-CT) scan was measured to predict surgical outcome.

Subjects and Method The correlation between ALT thickness and total reconstruction time was analyzed in 106 patients. The differences in ALT thickness between the successful and compromised-flap groups were analyzed retrospectively.

Results Median ALT thickness was $4.49 \mathrm{~mm}$, and total reconstruction time was $190 \mathrm{~min}$. Total reconstruction time was significantly correlated with ALT thickness $(p=0.019)$. ALT thickness, body mass index (BMI), total reconstruction time and ischemia time were significantly greater in the compromised-flap group than in the successful group. In the multivariate analysis, only BMI and ischemia time were predictors for the compromised flap.

Conclusion ALT thickness measured on a non-contrast image of PET-CT scan is useful as a surgical outcome predictor with respect to total reconstruction time. A further study may suggest the risk of a thick ALT in a compromised flap in head and neck reconstruction using an ALT free flap. Korean J Otorhinolaryngol-Head Neck Surg 2016;59(11):780-6

Key Words Cancer of head and neck · Computed tomography · Free flaps · Positron emission tomography $\cdot$ Thigh.

\section{Introduction}

The goal of surgery of head and neck cancer is complete re- section with minimal morbidity and preserved function. Free flaps have been used for several decades, and many refinements have been made. Due to the high success rate ( $>90 \%)$, 
the focus of most head and neck reconstruction is morbidity of the recipient and donor sites.

Anterolateral thigh (ALT) free flaps are a popular option. This flap is based on septocutaneous vessels or musculocutaneous perforators from the descending branch of the lateral circumflex femoral artery ${ }^{1)}$ and has low donor site morbidity, a large amount of skin, and a long pedicle. Another advantage of ALT flaps is that thickness can be adjusted to the subdermal level.

However, we have experienced difficulties in harvesting, insetting, and thinning thick ALT grafts. The thick layer of thigh fat that is often found in patients from Western countries may be a reason for the reduced use of ALT flaps. ${ }^{2,3)}$ Therefore, we investigated the association between ALT thickness and subdivided time-dependent surgical convenience. ALT thickness was measured on a non contrast image of preoperative positron emission tomography-computed tomography (PET-CT) scans, which are routinely performed to all of ALT free flap candidate in our department because it is essential for head and neck oncological staging. We hypothesized that ALT thickness could be used to predict flap compromise by comparing data from patients with successful and compromised flaps.

\section{Subjects and Method}

In total, 106 patients underwent head and neck reconstruc- tion with an ALT free flap by the same surgeon at the University College between May 2013 and February 2015. We retrospectively reviewed the medical records of all patients. Variations in the perforators were evaluated intraoperatively, not by preoperative thigh CT angiography or Doppler ultrasonography. We used the low-level axial view on a non contrast image of the preoperative PET-CT scans to measure ALT flap thickness (Fig. 1). Preoperatively we cannot expect the exact area of harvest due to vascular variation. We measured the thinnest thickness of upper lateral quadrant fasciocutaneous flap above the vastus lateralis at the consistent axial level of thigh (the lowest level of examined axial images). The upper lateral quadrant was defined by the lateral border line and mid horizontal line of femur. After completing the primary tumor resection, microvascular reconstruction with loupes $(\times 3.5)$ eyewear was performed and subdivided total operation times [ALT harvesting time, ischemia time (artery anastomosis time), and time to inset flap and anastomose the vein], final flap size, and pedicle length were recorded (Fig. 2). The lateral femoral cutaneous nerve and the motor branches to the vastus lateralis and rectus femoralis were preserved while dissecting the ALT flaps. The donor site was closed primarily in all patients. Subdermal thinning was adopted to adjust the ALT free flap for a difficult inset. The ALT was trimmed to the subdermal fat level, which added operation time. We analyzed the correlation between total reconstruction time and demographics and flap-related data for the pa-
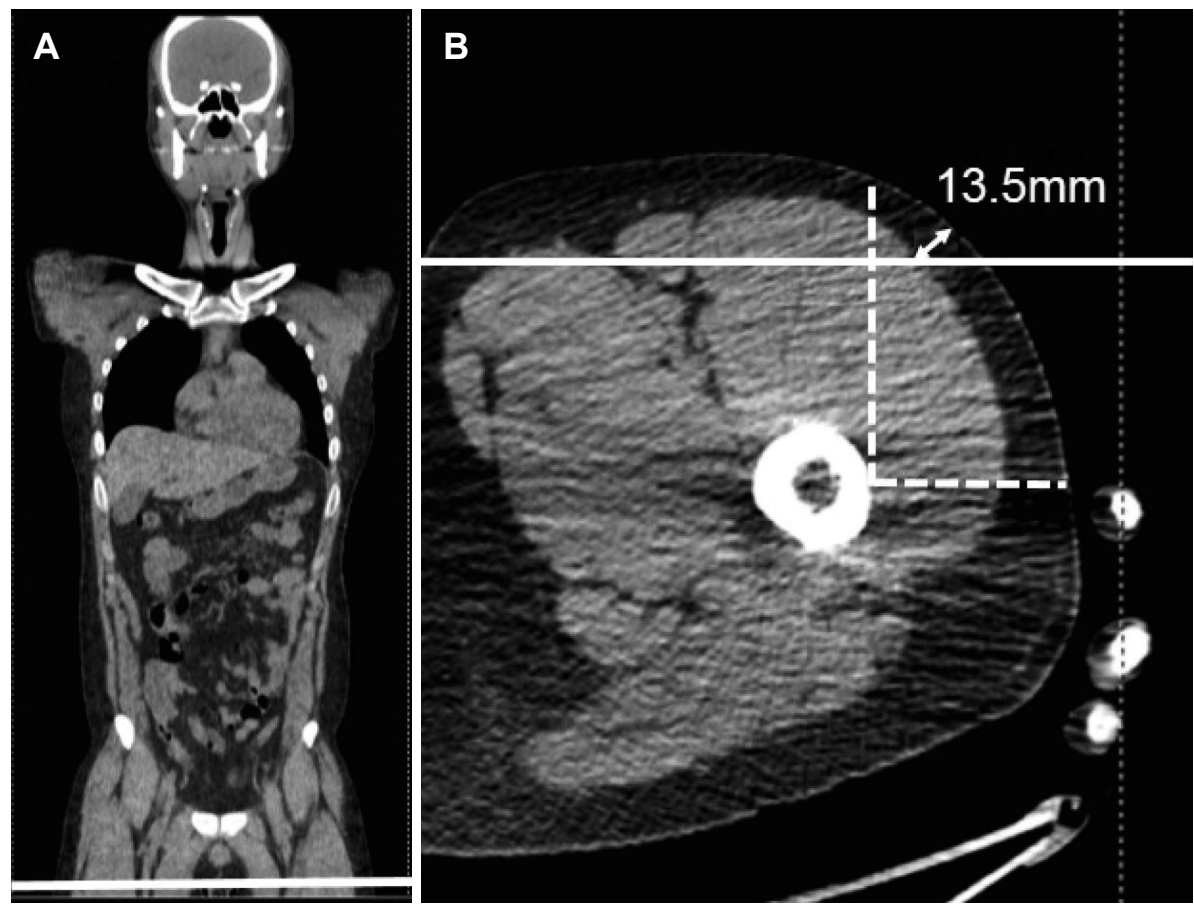

Fig. 1. Measurement of anterolateral thigh flap thickness on a non contrast image of preoperative positron emission tomography-computed tomography (PET-CT). At the lowest level of non contrast axial images of PET-CT (A), the thinnest thickness of upper lateral quadrant fasciocutaneous flap was measured above the vastus lateralis $(\mathrm{B})$. 
tients, including ALT thickness.

Yu, et al. ${ }^{4)}$ reported the definition of flap compromise based on an analysis of 49 cases. We used the concept of a compromised flap to evaluate the usefulness of ALT thickness because clinically compromised flap is more important to save the flaps threatened to fail and finding out the predictor of few free flap failure is more difficult in statistical analysis. The patients were kept in a surgical intensive care unit postoperatively on mechanical ventilation and were extubated the following morning. Residents or nurses monitored the free flap hourly for the first 3 days. The surgeon reviewed the possibility of vascular compromise by exploration during or after the operation if there were any changes in the skin color of the flap, skin prick test results, or Doppler ultrasounds. Differences in parameters, including ALT thickness, in the successful and compromised-flap groups were analyzed. This study was approved by the institutional review board. Written informed consent was obtained from all patients before surgery.

\section{Statistics}

PASW 18.0 software (SPSS Inc., Chicago, IL, USA) was used for the statistical analysis. Bivariate correlation analysis, partial correlation analysis, the Mann-Whitney test, Fisher's exact test, and binary logistic regression analysis were used where appropriate. A $p$-value $<0.05$ was considered significant.

\section{Results}

\section{Patient demographics}

In total, 106 patients [79 males (74.5\%); median age, 57 years] with head and neck cancer who underwent an ALT free-flap procedure were analyzed. Table 1 shows the patients' characteristics. The median body mass index (BMI) was 22.48 $\left(\mathrm{kg} / \mathrm{m}^{2}\right)$. Most primary tumors were squamous cell carcinoma, representing 97 cases (91.5\%). Twenty-two patients (20.7\%) had undergone previous treatments (surgery, radiation, or chemotherapy). The left ALT (89.6\%) was preferred for ease of operative preparation, considering the locations of the attending surgeon and the anesthesiologist. The most common primary site was the oral cavity ( $n=48$ ), including 12 total glossectomies. Pharyngolaryngeal tumors were resected in 47 cases, including 12 total laryngectomies. Other primary sites included the maxilla, orbit, parotid gland, external auditory canal, and nasal vestibule.
Table 1. Patient characteristics $(n=106)$

\begin{tabular}{|c|c|c|}
\hline Demographic parameters & Median & IQR \\
\hline Age (years) & 57 & $51-65.7$ \\
\hline $\mathrm{BMI}\left(\mathrm{kg} / \mathrm{m}^{2}\right)$ & 22.48 & $20.0-24.4$ \\
\hline Oncologic parameters & Count & $\%$ \\
\hline \multicolumn{3}{|l|}{ Histology } \\
\hline Squamous cell carcinoma & 97 & 91.5 \\
\hline Adenoid cystic carcinoma & 4 & 3.7 \\
\hline Salivary ductal carcinoma & 2 & 1.8 \\
\hline Mucoepidermoid carcinoma & 2 & 1.8 \\
\hline Adenocarcinoma & 1 & 0.9 \\
\hline \multicolumn{3}{|l|}{ Primary tumor localization } \\
\hline Oral cavity & 48 & 45.2 \\
\hline Oropharynx & 24 & 22.6 \\
\hline Hypopharynx & 17 & 16 \\
\hline Larynx & 7 & 6.6 \\
\hline Other & 10 & 9.4 \\
\hline \multicolumn{3}{|l|}{ T stage } \\
\hline $\mathrm{T1}$ & 11 & 10.3 \\
\hline $\mathrm{T} 2$ & 38 & 35.8 \\
\hline T3 & 30 & 28.3 \\
\hline $\mathrm{T} 4$ & 27 & 25.4 \\
\hline \multicolumn{3}{|l|}{ Previous treatment } \\
\hline Chemotherapy and/or radiation & 17 & 16.0 \\
\hline Operation & 5 & 4.7 \\
\hline Fresh & 84 & 79.2 \\
\hline
\end{tabular}

IQR: interquartile range, BMI: body mass index

\section{Operative characteristics}

The measured median ALT thickness on a non contrast image of PET-CT at consistent axial level was $4.49 \mathrm{~mm}$. Final ALT flap size (median, $47 \mathrm{~cm}^{2}$ ) was calculated at the $1 \mathrm{~cm}$ grid paper. Most patients started an oral diet (median, 14 days) after decannulation (median, 12 days). Total reconstruction time (median, $190 \mathrm{~min}$ ) was subdivided into three operating time variables [ALT harvest time, ischemia time (artery anastomosis time), and time to inset flap and anastomose the vein] recorded individually (Fig. 2). The operation variables are shown in Table 2.

\section{Microvascular flap compromise}

Microvascular compromise (intraoperative and postoperative) occurred in 16 cases (15\%, Table 3$)$. The surgeon confirmed vascular compromise based on the skin color of the flap, skin prick test results, or Doppler monitoring. After revising the anastomoses, seven flaps (43\%) survived after intra- or postoperative management. Two cases (arterial reanastomosis for arterial spasm) were managed well by intraoperative exploration. Another five cases [vein re-anastomosis $(n=2)$, 


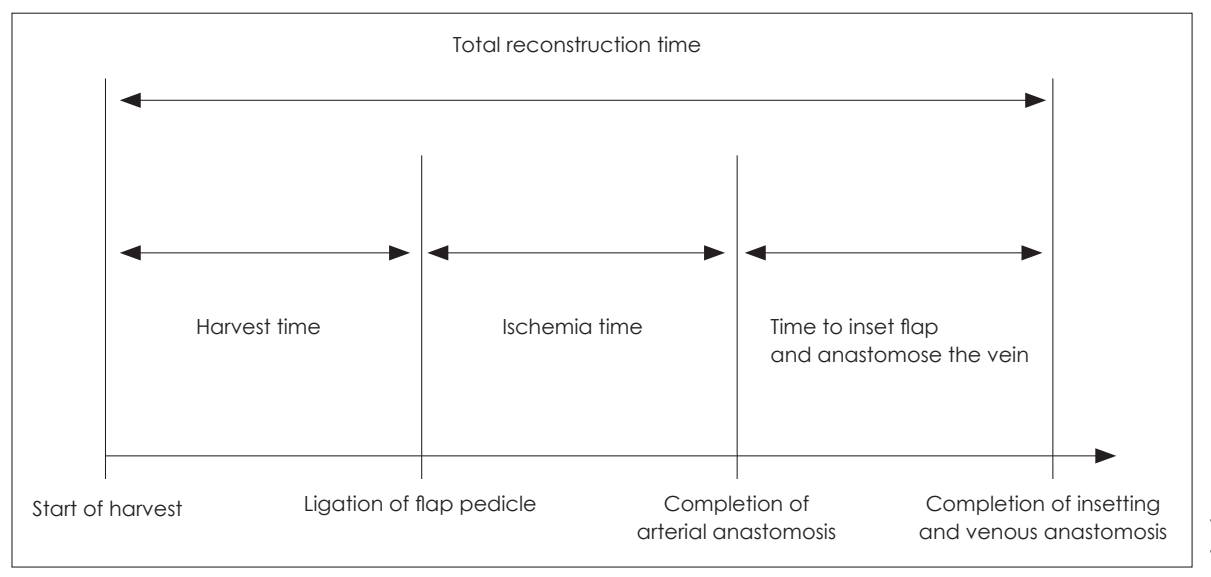

Fig. 2. Three operative variables (harvest time, ischemia time, and time to inset flap and anastomose the vein).

Table 2. Operation-based characteristics $(n=106)$

\begin{tabular}{|c|c|c|}
\hline Parameters & Median & IQR \\
\hline \multicolumn{3}{|l|}{ Flap data } \\
\hline Flap size $\left(\mathrm{cm}^{2}\right)$ & 47 & $35.5-56.5$ \\
\hline Pedicle length $(\mathrm{cm})$ & 11 & $10-12$ \\
\hline ALT flap thickness in PET-CT (mm) & 4.49 & $2.49-6.90$ \\
\hline \multicolumn{3}{|l|}{ Functional recovery day (POD) } \\
\hline Decannulation day & 12 & $9-18$ \\
\hline Oral diet start day & 14 & $10.25-19.8$ \\
\hline \multicolumn{3}{|l|}{ Operation time (minutes) } \\
\hline ALT harvesting time & 63.5 & $48.5-79.8$ \\
\hline $\begin{array}{l}\text { Ischemia time (artery anastomosis } \\
\text { time) }\end{array}$ & 65 & $50.0-94.3$ \\
\hline $\begin{array}{l}\text { Time to inset flap and anastomose } \\
\text { the vein }\end{array}$ & 60.5 & $40.0-82.3$ \\
\hline Total reconstruction time & 190 & $155-240$ \\
\hline
\end{tabular}

medical leech therapy $(\mathrm{n}=1)$, and bleeding control at the anastomosis site $(n=2)$ survived successfully after postoperative management. Venous congestion or thrombosis was the most common cause of compromised flap (43\%; 7 of 16 compromised flaps)].

\section{Complications}

Overall, nine cases $(8.4 \%)$ failed despite revision of flaps with vascular compromise. Failed ALT flaps were evaluated during postoperative revision. Venous congestion or thrombosis was the main cause of failure (four cases), while two cases of thrombosis were due to uncontrolled cervical fistula. In total, four cases of cervical fistula led to prolonged hospital stays, but two were well controlled by local compression. Three flaps failed due to arterial insufficiency. Anastomosis bleeding and a venous anomaly caused two flaps to fail. The tracheal tubes for preventing airway obstruction due to bulky
Table 3. Postoperative complications $(n=106)$

\begin{tabular}{lcc}
\hline & Count & $\%$ \\
\hline Vascular compromised flap* & 16 & 15 \\
Flap failure & 9 & 8.4 \\
Cervical fistula & 4 & 3.7 \\
Postoperative bleeding & 2 & 1.8 \\
Delayed donor wound healing & 0 & 0 \\
Persistent tracheal cannulation & 0 & 0 \\
Persistent PEG & 4 & 3.7 \\
Mortality & $1 \dagger$ & 0.9 \\
\hline
\end{tabular}

*surgeon identified based on skin color change, prick test, or Doppler US monitoring, †postoperative pneumonia. PEG: percutaneous endoscopic gastrostomy

free flaps were decannulated successfully in all patients. The percutaneous endoscopic gastrostomy (PEG) tube was maintained in four patients due to poor swallowing. A 73-year-old female patient died due to postoperative pneumonia. Details of the postoperative complications are presented in Table 3. The percentage of cervical fistula or persistent PEG tubes may have been underestimated because the total number of ALT flaps included primary sites with no risk for complications.

\section{Correlation between total reconstruction time and ALT thickness}

After adjusting for confounding factors, total reconstruction time was correlated with ALT thickness (partial correlation coefficient $r=0.212, p=0.036$ ). Confounding factors were selected from the bivariate correlation test. Various factors (age, BMI, T stage, three subdivided operation times, flap size, pedicle length, decannulation day, and oral diet start day) were analyzed for their association with total reconstruction time (Table 4). Old age was strongly correlated with total reconstruction time and ALT thickness $(p<0.01)$. The three operation time variables were correlated with total recon- 
Table 4. Correlation between total reconstruction time, ALT thickness, and other variables

\begin{tabular}{lcc}
\hline \multicolumn{1}{c}{ Parameters } & $\begin{array}{c}\text { Total reconstruction } \\
\text { time }\left(\mathrm{r}^{*}\right)\end{array}$ & p value \\
\hline $\begin{array}{l}\text { ALT thickness (partial } \\
\text { correlation test') }\end{array}$ & 0.236 & $0.019^{\ddagger}$ \\
$\begin{array}{l}\text { ALT thickness (bivariate } \\
\text { correlation test) }\end{array}$ & 0.134 & 0.173 \\
Age & -0.263 & $0.007^{\ddagger}$ \\
BMI & 0.183 & 0.061 \\
T stage & 0.073 & 0.460 \\
ALT harvesting time & 0.562 & $0.000^{\ddagger}$ \\
Ischemia time (artery & 0.664 & $0.000^{\ddagger}$ \\
$\quad$ anastomosis time) & & \\
Time to inset flap and & 0.514 & $0.000^{\ddagger}$ \\
$\quad$ anastomose the vein & & \\
Flap size & 0.141 & 0.151 \\
Pedicle length & 0.293 & $0.002^{\ddagger}$ \\
Decannulation day & 0.189 & 0.107 \\
Oral diet start day & 0.118 & 0.250 \\
\hline
\end{tabular}

*correlation coefficients (Spearman's rho $=r$ ) were calculated, tadjusted by significant confounding factor: age, ALT harvest time, ischemia time, time to inset flap and anastomose the vein, pedicle length, $\neq p<0.05$. ALT: anterolateral thigh, BMl: body mass index struction time $(p<0.01)$. Long pedicle length was correlated with harvest time and consequently resulted in a longer total reconstruction time $(p<0.01)$. BMI was correlated with ALT thickness but not with total reconstruction time (Supplementary Table 1 in the online-only Data Supplement).

\section{Differences in ALT thickness between the successful and compromised-flap groups}

ALT thickness differed significantly between the successful and compromised groups $(p=0.003)$ (Table 5). Interestingly, ischemia ( $p=0.032)$ and total reconstruction $(p=0.03)$ times were time factors related to compromised flaps. Adjusted odds ratios of each factor were tested by multivariate logistic regression to compare the risk of each significant predisposing factor. In this model, BMI and ischemia time showed significant risks related to flap compromise (Table 6).

\section{Discussion}

Various types of free flaps are used to reconstruct head and

Table 5. Univariate comparison between the successful and compromised-flap groups

\begin{tabular}{lccc}
\hline & $\begin{array}{c}\text { Successful flap } \\
\text { patients }(\mathrm{n}=87)\end{array}$ & $\begin{array}{c}\text { Compromised flap } \\
\text { patients }(\mathrm{n}=16)\end{array}$ & $p$-value* \\
\hline Age (years) & $57(28-79)$ & $56(24-72)$ & 0.146 \\
$\mathrm{BMI}\left(\mathrm{kg} / \mathrm{m}^{2}\right)$ & $22.4(14.3-29.4)$ & $23.4(20.8-29.4)$ & $0.005^{\dagger}$ \\
T stage & $3(1-4)$ & $3(2-4)$ & 0.290 \\
ALT harvesting time (minutes) & $64(23-155)$ & $52(31-171)$ & 0.531 \\
Ischemia time (minutes) (artery anastomosis time) & $65(26-1396)$ & $70(34-260)$ & $0.032^{\dagger}$ \\
Time to inset flap and anastomose the vein & $62(39-240)$ & $46(37-173)$ & 0.883 \\
Total reconstruction time (minutes) & $195(115-140)$ & $215(136-501)$ & $0.030^{\dagger}$ \\
Flap size $\left(\mathrm{cm}{ }^{2}\right)$ & $47(16.5-94.2)$ & $47(22.9-94.2)$ & 0.380 \\
Pedicle length (cm) & $11(8-15)$ & $11(7-16)$ & 0.689 \\
ALT thickness (mm) & $3.65(0.3-14.6)$ & $7.2(2.36-13.93)$ & $0.0033^{\dagger}$ \\
Decannulation day (POD) & $12(4-65)$ & $16(10-48)$ & 0.056 \\
Oral diet start day (POD) & $13(7-50)$ & $12(10-56)$ & $0.048^{\dagger}$ \\
Gender (male) & $67(74.4 \%)$ & $12(75.0 \%)$ & 0.607 \\
Primary site with risk of cervical salivary leak & $79(87.8 \%)$ & $2(12.5 \%)$ & 0.170 \\
Previous radiotherapy & $11(12.6 \%)$ & 0.975 \\
\hline
\end{tabular}

*tested by Mann-Whitney test and Fischer's exact test, ${ }^{\dagger} p<0.05$. BMl: body mass index, ALT: anterolateral thigh, POD: post-operative day

Table 6. Logistic regression results for predicting a compromised flap

\begin{tabular}{|c|c|c|c|c|c|c|}
\hline & \multicolumn{3}{|c|}{ Univariate } & \multicolumn{3}{|c|}{ Multivariate* } \\
\hline & Unadjusted OR & $95 \% \mathrm{Cl}$ & $p$ value & Adjusted OR & $95 \% \mathrm{Cl}$ & $p$ value \\
\hline BMI & 1.248 & $1.058-1.473$ & $0.009^{\dagger}$ & 1.253 & $1.046-1.500$ & $0.014^{\dagger}$ \\
\hline Ischemia time (artery anastomosis time) & 1.012 & $1.004-1.020$ & $0.003^{\dagger}$ & 1.011 & $1.003-1.020$ & $0.007+$ \\
\hline Total reconstruction time & 1.007 & $1.001-1.013$ & $0.020^{\dagger}$ & & & \\
\hline ALT thickness & 1.201 & $1.052-1.370$ & $0.007^{\dagger}$ & & & \\
\hline
\end{tabular}

*adjusted OR by the significant factors listed in Table 5, ${ }^{\dagger} p<0.05$. OR: odds ratio, Cl: confidence interval, BMl: body mass index, ALT: anterolateral thigh 
neck defects. Among them, the ALT free flap is the most popular due to its minimal morbidity and versatility. However, the large bulk of an ALT flap can decrease pliability and limit its clinical application in patients with high BMI or thick thighs. ${ }^{5}$ Although the surgeon can harvest the ALT flap, the increased time and effort is a major shortcoming of ALT free flaps, particularly in patients with a high BMI. To overcome this disadvantage, Kimura and Satoh ${ }^{6}$ suggested a thinning method, which spares the subdermal plexus circulation via peripheral defatting and preserves the adipose tissue around the perforating vessel. If a thin flap is necessary, a suprafascial technique can be used, even though the procedure may be technically difficult and can lead to flap failure. ${ }^{7-9)}$ Thinned ALT flaps and other fasciocutaneous-free flaps have been accepted as a reliable option after further research. Camaioni, et al. ${ }^{10)}$ demonstrated that a thinned ALT free flap can replace a radial forearm free flap due to its low donor site morbidity and acceptable functional results.

Although most patients in our study had a relatively low median BMI $\left(22.48 \mathrm{~kg} / \mathrm{m}^{2}\right)$, the technically advanced thinning method was applied to some patients with thick subcutaneous fat, resulting in longer operation times. Our study verified that ALT thickness was associated with increased total reconstruction times (partial correlation coefficient; $r=0.236$, $p=0.019$ ) (Table 4). Operation time was confounded by many factors, but we tried to exclude their effects. All operations were performed by the same experienced surgeon, and times were recorded independently to reduce bias. Difficulties with donor vessel availability, extent of the recipient's defect, and inset difficulties were indirectly related to harvest time, pedicle length, $\mathrm{T}$ stage, flap size, and inset time. Some authors have revealed an increased risk for flap failure in cases with a thinned flap size $\left(>150 \mathrm{~cm}^{2}\right){ }^{11)}$ Such intraoperative difficulties would affect operation time. However, our data showed no association between flap size and operation time or compromised flaps.

ALT thickness and BMI were significantly higher in the compromised-flap group than in the successful group (Table 5). Although a high BMI is correlated with a thick ALT, only $\mathrm{BMI}$ and ischemia time were significant risk factors for flap compromise in our study (Table 6). Yu, et al. ${ }^{4}$ analyzed the effects of sex, surgeon experience, and type of defect on flap compromise (49 of 1310 cases) and failed head and neck reconstruction. They unexpectedly discovered that the compromised-flap rate was twice as high in female patients. The cause of the higher rate was not clear, but may have been due to low statistical power and more frequent thrombogenic events in women. ${ }^{4)}$ Women have more subcutaneous fat; thus, we speculate that their result was caused by thicker flaps in women. Our female patients had thicker ALTs compared with those of male patients ( $p<0.05$; two-sample t-test), similar to the findings of other studies. However, the percentages of compromised flaps were nearly the same for both sexes in our study (Table 5). Chang, et al. ${ }^{12)}$ also reported that no patient-related factors (age, BMI, smoking, diabetes mellitus, hypertension, coronary artery disease, deep vein thrombosis, or chemoradiation) were associated with an increased risk for flap loss in 2296 cases. Therefore, no study has reported that BMI or ALT thickness is a risk for flap compromise. We have provided more details regarding the correlation between ALT thickness and flap outcome than previous studies, and a further larger scale study may suggest that ALT thickness is more accurate than BMI for predicting surgical outcome because subcutaneous fat distribution varies according to sex and donor site.

ALT thickness is most accurately measured intraoperatively but is meaningless for deciding the preoperative usefulness of a donor site. We selected preoperative PET-CT, because all subjects underwent PET-CT for oncologic staging of head and neck, and the scan includes the lower thigh. In our department, we prefer to select perforators intraoperatively, so expensive CT angiography or ultrasonography is not used routinely. Gong and $\mathrm{Wu}^{13)}$ reported precise measurements of subcutaneous thigh flap fat in 66 Chinese patients, but those subjects had thicker lower thighs and thicker flaps (male, 8.70 \pm 3.67 ; female, $14.91 \pm 4.81 \mathrm{~mm}$ ) than our radiological measurements (median, $4.49 \mathrm{~mm}$; interquartile range, 2.49-6.90 mm).

Additionally, we found an insignificant association between ALT thickness and functional disability. Most patients started an oral diet and were decannulated 2 weeks after surgery, which was considered to represent functional recovery. Delayed functional recovery time did not correlate with ALT thickness (Supplementary Table 1 in the online-only Data Supplement). However, our evaluation of functional disability was limited to immediate postoperative care. Long-term functional outcomes including unsatisfactory deformities or dysphagia need to be studied further considering shrinkage of a transferred free flap.

The clinical significance of a compromised flap was also reviewed. Patients in the compromised-flap group required additional exploratory surgery and 25\% (4 of 16, all patients 
with a cervical fistula had compromised flaps) experienced a cervical fistula (Table 3). Patients in the compromised-flap group were decannulated and started an oral diet later but only the oral diet start day was statistically significant ( $p=0.056$ and 0.048 , respectively). The percentages of primary sites with potential possible salivary leakage (below the oral cavity) did not differ between the two groups, so salivary exposure was not a risk for flap compromise in this study (Table 5). Ischemia time was another risk factor predicting compromised flaps in the multivariate logistic regression model. According to the results, our effort to reduce the ischemia time for successful free flaps was reasonable (Table 6).

This study had some limitations given its retrospective design and the confounding factors affecting operation time. We tried to reduce bias. The ALT thickness in this study should be compared to the ultrasound or intraoperative measurement. Our results provide insight into the role of ALT flap thickness as a predictor of operation time, flap compromise, and functional disability.

\section{Supplementary Materials}

The online-only Data Supplement is available with this article at https://doi.org/10.3342/kjorl-hns.2016.59.11.780.

\section{Acknowledgments}

This work was supported by the Soonchunhyang University Research Fund.

\section{REFERENCES}

1) Lakhiani C, Lee MR, Saint-Cyr M. Vascular anatomy of the anterolateral thigh flap: a systematic review. Plast Reconstr Surg
2012;130(6):1254-68.

2) Yu P, Sanger JR, Matloub HS, Gosain A, Larson D. Anterolateral thigh fasciocutaneous island flaps in perineoscrotal reconstruction. Plast Reconstr Surg 2002;109(2):610-6; discussion 617-8.

3) $\mathrm{Yu}$ P. Characteristics of the anterolateral thigh flap in a Western population and its application in head and neck reconstruction. Head Neck 2004;26(9):759-69.

4) Yu P, Chang DW, Miller MJ, Reece G, Robb GL. Analysis of 49 cases of flap compromise in 1310 free flaps for head and neck reconstruction. Head Neck 2009;31(1):45-51.

5) Lin DT, Coppit GL, Burkey BB. Use of the anterolateral thigh flap for reconstruction of the head and neck. Curr Opin Otolaryngol Head Neck Surg 2004;12(4):300-4.

6) Kimura N, Satoh K. Consideration of a thin flap as an entity and clinical applications of the thin anterolateral thigh flap. Plast Reconstr Surg 1996;97(5):985-92.

7) Wei FC, Jain V, Celik N, Chen HC, Chuang DC, Lin CH. Have we found an ideal soft-tissue flap? An experience with 672 anterolateral thigh flaps. Plast Reconstr Surg 2002;109(7):2219-26; discussion 2227-30.

8) Mäkitie AA, Beasley NJ, Neligan PC, Lipa J, Gullane PJ, Gilbert RW. Head and neck reconstruction with anterolateral thigh flap. Otolaryngol Head Neck Surg 2003;129(5):547-55.

9) Yildirim S, Avci G, Aköz T. Soft-tissue reconstruction using a free anterolateral thigh flap: experience with 28 patients. Ann Plast Surg 2003;51(1):37-44.

10) Camaioni A, Loreti A, Damiani V, Bellioni M, Passali FM, Viti C. Anterolateral thigh cutaneous flap vs. radial forearm free-flap in oral and oropharyngeal reconstruction: an analysis of 48 flaps. Acta Otorhinolaryngol Ital 2008;28(1):7-12.

11) Sharabi SE, Hatef DA, Koshy JC, Jain A, Cole PD, Hollier LH Jr. Is primary thinning of the anterolateral thigh flap recommended? Ann Plast Surg 2010;65(6):555-9.

12) Chang EI, Zhang H, Liu J, Yu P, Skoracki RJ, Hanasono MM. Analysis of risk factors for flap loss and salvage in free flap head and neck reconstruction. Head Neck 2016;38 Suppl 1:E771-5.

13) Gong ZJ, Wu HJ. Measurement for subcutaneous fat and clinical applied anatomic studies on perforators in the anterior thigh region. J Oral Maxillofac Surg 2013;71(5):951-9. 
Supplementary Table 1. Correlation between ALT thickness and other variables

\begin{tabular}{lc}
\hline & ALT thickness $\left(\mathrm{r}^{*}\right)$ \\
\hline Age & $-0.297^{\dagger}$ \\
BMl & $0.285^{\dagger}$ \\
T stage & 0.032 \\
Flap size & -0.043 \\
Pedicle length & 0.064 \\
Decannulation day & 0.006 \\
Oral diet start day & -0.013 \\
\hline
\end{tabular}

*correlation coefficients (Spearman's rho=r) were tested by bivariate correlation analysis, $t p<0.05$. BMl: body mass index, ALT: anterolateral thigh 